\title{
Regulation of liver development: implications for liver biology across the lifespan
}

\author{
Philip A Gruppuso1,2 and Jennifer A Sanders ${ }^{1,3}$ \\ 'Division of Pediatric Endocrinology, Rhode Island Hospital and Brown University, Providence, RI, USA \\ 2Department of Molecular Biology, Cell Biology and Biochemistry, Brown University, Providence, RI, USA \\ ${ }^{3}$ Department of Pathology and Laboratory Medicine, Brown University, Providence, RI, USA
}

Correspondence should be addressed to P A Gruppuso Email Philip_Gruppuso@brown.edu

\begin{abstract}
The liver serves a spectrum of essential metabolic and synthetic functions that are required for the transition from fetal to postnatal life. Processes essential to the attainment of adequate liver mass and function during fetal life include cell lineage specification early in development, enzymic and other functional modes of differentiation throughout gestation, and ongoing cell proliferation to achieve adequate liver mass. Available data in laboratory rodents indicate that the signaling networks governing these processes in the fetus differ from those that can sustain liver function and mass in the adult. More specifically, fetal hepatocytes may develop independent of key mitogenic signaling pathways, including those involving the Erk mitogenactivated protein kinases MAPK $1 / 3$ and the mechanistic target of rapamycin (mTOR). In addition, the fetal liver is subject to environmental influences that, through epigenetic mechanisms, can have sustained effects on function and, by extension, contribute to the developmental origin of adult metabolic disease. Finally, the mitogen-independent phenotype of rat fetal hepatocytes in late gestation makes these cells suitable for cellbased therapy of liver injury. In the aggregate, studies on the mechanisms governing fetal liver development have implications not only for the perinatal metabolic transition but also for the prevention and treatment of liver disorders throughout the lifespan.
\end{abstract}

\section{Key Words \\ - development \\ - epigenetics \\ - growth factors \\ - insulin action \\ - metabolism}

\section{Introduction}

The liver is essential to a panoply of metabolic, synthetic, and other physiologic functions that are required for the viability of the fetus and, in turn, the offspring during the perinatal transition (Cowett 2011). Liver development from mid-gestation to term may be thought of as comprising two interrelated but distinct processes, growth in liver mass and functional differentiation. The net result of these two processes is sufficient capacity for the liver to ensure metabolic homeostasis during and beyond parturition, an effective transition to the enteral acquisition of nutrients, and adequate synthetic function to ensure the physiologic well-being of the newborn.

This review focuses on several areas: early liver development, including cell lineage specification; basic mechanisms regulating functional differentiation gleaned from studies in the late gestation fetal rat; signaling pathways involved in the regulation of liver mass during rodent development; nonhuman primate studies on the role of insulin in liver development; maternal nutrition and fetal programing as they affect liver physiology; and the 
application of the fetal hepatocyte phenotype to cell-based therapy for liver disease. We focus, in part, on our own work on late gestation liver development in the rodent. However, we also focus on a well-established literature on the role of hormones in liver enzymic differentiation as well as contemporary studies on liver epigenetics and cell signaling.

\section{Early liver development and cell lineage specification}

The temporal sequence of events that comprise normal liver development can be aligned in the laboratory rat and human based on a number of specific characteristics and changes (Fig. 1). This allows one to extrapolate from often employed rodent models to humans and nonhuman primates. This review focuses on data derived from the laboratory rat and from the Rhesus monkey.

The adult human liver is composed of four lobes with hepatocytes, the major parenchymal cell type, constituting approximately $80 \%$ of the liver mass. Hepatocytes and cholangiocytes (biliary epithelial cells) are derived from the definitive endoderm, which is formed during the third week of human gestation (Wilson et al. 1963, Bort et al. 2006). Transforming growth factor $\beta$, WNT, fibroblast growth factor, $\mathrm{NOTCH}$, and bone morphogenic protein control the key signaling pathways for hepatogenesis (Si-Tayeb et al. 2010). The spatial and temporal regulation as well as the mechanisms by which these pathways contribute to liver development has been elucidated (reviewed in Gordillo et al. 2015). The convergence of the ventral portion of the endoderm adjacent to the cardiac mesoderm and septum transversum results in hepatic specification. The liver bud is formed when hepatic endodermal cells, termed hepatoblasts, proliferate and migrate into the septum transversum around gestational day 28 in the human and day 12 in the rat (Wilson et al. 1963, Severn 1971, Hutchins \& Moore 1988, Shiojiri et al. 1991, Bort et al. 2006). Bipotential hepatoblasts express alpha-fetoprotein (AFP) as well as markers for both hepatocytes (albumin, hepatocyte nuclear factor (HNF)4, keratin 8, and keratin 18) and cholangiocytes (keratin 19) (Cascio \& Zaret 1991, Shiojiri et al. 1991, Nava et al. 2005).

Hepatoblasts located near the portal vein give rise to cholangiocyte precursors, whereas those located away from the portal vein become hepatocytes.

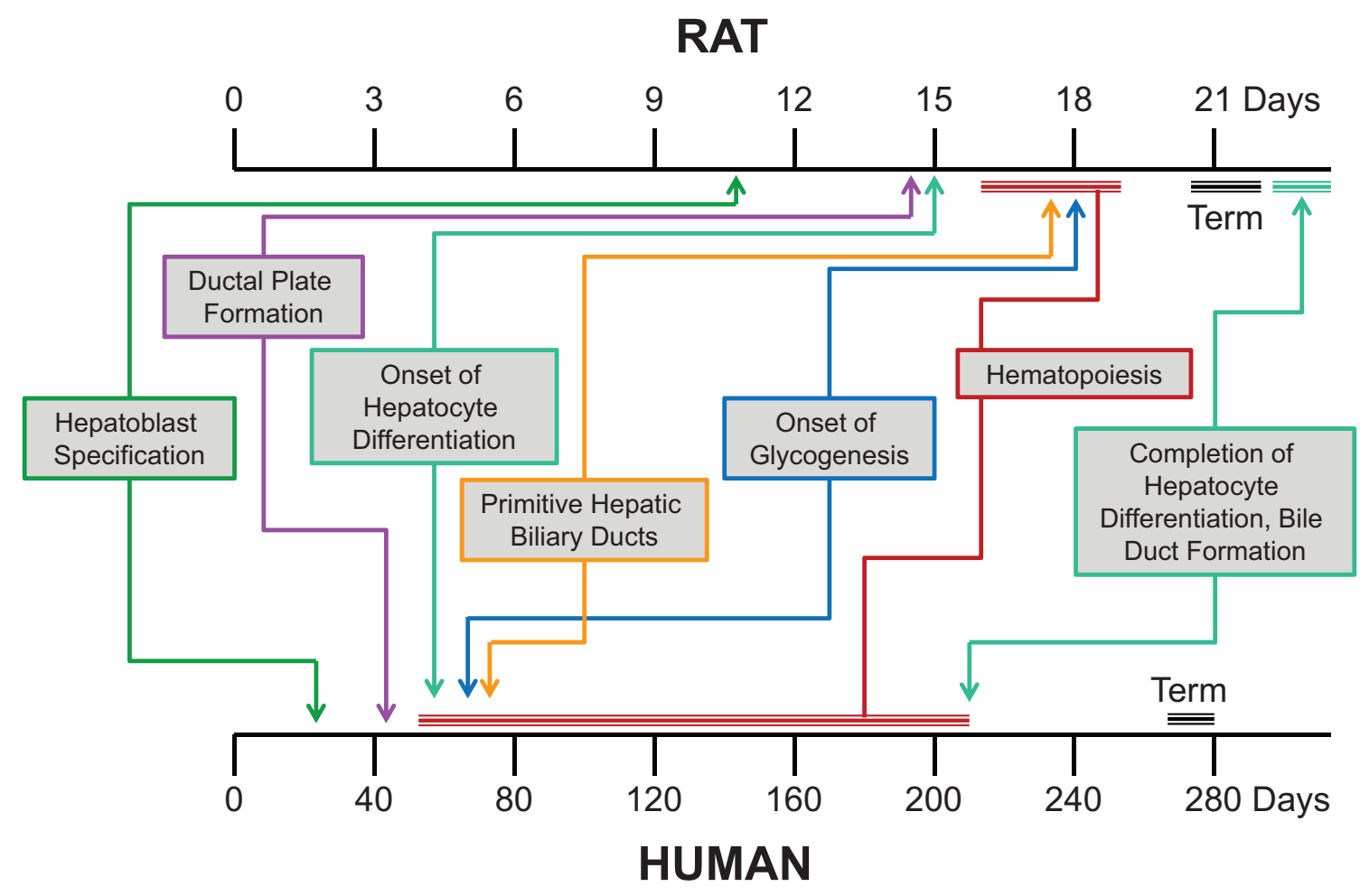

Figure 1

A timeline of liver development in the rat and human. Developmental milestones are plotted on two scales that represent the duration of gestation in rats and humans. The schematic is based on published data (Shiojiri et al. 1991, Gordillo et al. 2015).

http://jme.endocrinology-journals.org DOI: 10.1530/JME-15-0313
C 2016 Society for Endocrinology Printed in Great Britain
Published by Bioscientifica Ltd 
Hepatocytic differentiation begins during the eighth week of gestation in humans and on day 15 in the rat. The process continues throughout the remainder of embryonic and postnatal development. Hepatocytes are heterogeneous, with their function largely determined by their localization within the liver lobule. This results in the compartmentalization of key enzymes and transporters, which in turn accounts for metabolic zonation of liver. The differentiation of hepatocytes is controlled by a complex network of transcription factors including HNF1A, HNF4, HNF1B, and FOXA2 (Kyrmizi et al. 2006). The fetal liver is the major site for hematopoiesis during embryonic development, with hematopoietic progenitors colonizing the liver bud soon after the cells invade the surrounding mesenchyme (Collardeau-Frachon \& Scoazec 2008). As hepatoblasts mature along a hepatic lineage, the cells no longer support hematopoiesis, consistent with the movement of hematopoietic cells to the bone marrow near the end of the second trimester in humans (Cumano \& Godin 2007, Collardeau-Frachon \& Scoazec 2008). Like hepatocytes, the cholangiocytes gradually mature, forming tubules at 14 weeks with remodeling of the ducts and termination of cholangiocyte differentiation occurring at approximately 30 weeks (Haruna et al. 1996). In the rat, the process begins at day 15.5 and terminates during the neonatal period (Shiojiri et al. 1991). Liver development and adult liver function are dependent on the coordinated interaction of hepatocytes, cholangiocytes, sinusoidal epithelial cells, Kupffer cells (liver-specific macrophages), stellate cells, pit cells (natural killer cells), and epithelial cells.

\section{Late gestation liver development in the rat}

At birth, the fetus makes an abrupt transition from placental nutrient supply to the utilization of endogenous sources to maintain metabolic homeostasis (Mayor \& Cuezva 1985). As is the case in the adult, the liver serves as a repository for stored carbohydrate in the form of glycogen and as a distribution center for peripheral nutrient stores, most notably fat in white adipose tissue and skeletal muscle protein. The utilization of these two peripheral sources of stored energy requires hepatic fatty acid oxidation, ketogenesis, and gluconeogenesis. The enzymatic machinery essential for these processes is induced through complex mechanisms that involve the regulation of gene expression at the levels of transcriptional control, RNA processing, RNA translation, and the post-translational processing and modification of proteins. For many years, investigation of this series of complex physiologic events employed the laboratory rat as a model system.

Enzymic differentiation of the liver in late gestation was long ago shown by Greengard and Dewey (1967) to be responsive to in situ administration of specific hormones to fetal rats. The study, which involved determination of fetal liver enzyme activities, showed that glucose6-phosphatase could be induced by cAMP-mediated hormones and by administration of thyroxine, but not by growth hormone. Similar results were obtained for tyrosine aminotransferase, a critical enzyme in amino acid metabolism. These studies were interpreted at the time as indicating that cAMP-mediated hormones are responsible for the induction of essential hepatic metabolic pathways, including gluconeogenesis, immediately following birth (Greengard 1969).

Girard et al. (1973), examining enzymic liver differentiation, noted that induction of the key rate-limiting enzymes for gluconeogenesis, phosphoenolpyruvate carboxykinase and glucose-6-phosphatase among others occurs, during the immediate postnatal period in the rat. These investigators attributed this enzyme induction to a sharp decrease in the insulin-to-glucagon ratio that coincided with a postnatal fall in serum glucose.

With regard to a direct role for insulin, work by Porterfield (1979) indicated that insulin plays a limited prenatal role. While insulin could suppress the induction of glucose-6-phosphatase, it could do so only during the immediate preterm period. These data are consistent with our own observations regarding the expression and activity of the insulin signaling network in the late gestation fetal rat (Fig. 2). Insulin receptor abundance and insulininduced receptor self-phosphorylation are reduced at the end of gestation relative to in the adult animal (Gruppuso et al. 1991, Anand et al. 2002, Khamzina et al. 2003). More impressive is the very low level with which insulin receptor substrate (IRS)-1 is expressed at the protein level in late gestation liver. This low level of IRS1 content is reflected in impaired IRS1 tyrosine phosphorylation and IRS1-mediated signaling to phosphatidylinositol-3 kinase (PI3K). IRS2, a paralog of IRS1, is preferentially expressed in fetal liver. Its tyrosine phosphorylation and ability to mediate activation of PI3K is high in the late gestation fetus relative to the adult. However, signaling to two downstream kinases, Akt and S6 kinase 1, is markedly attenuated in the fetus, indicating an uncoupling of the pathway downstream from PI3K in late gestation.

The older literature on enzymic differentiation, along with our studies on insulin signaling, supports the conclusion that liver growth and functional differentiation

Published by Bioscientifica Ltd. 

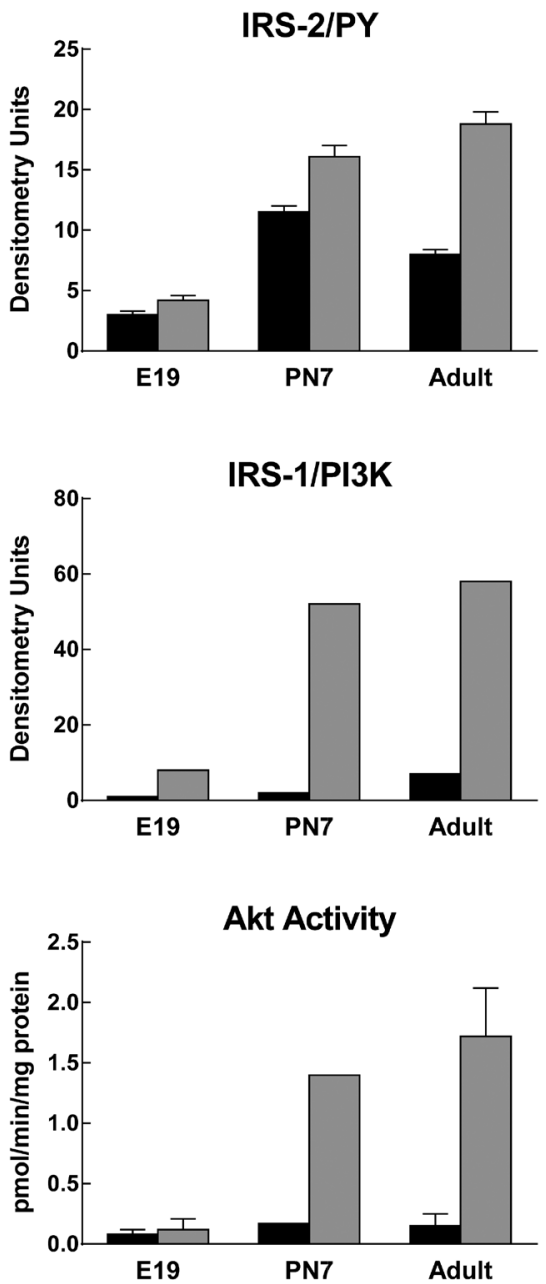
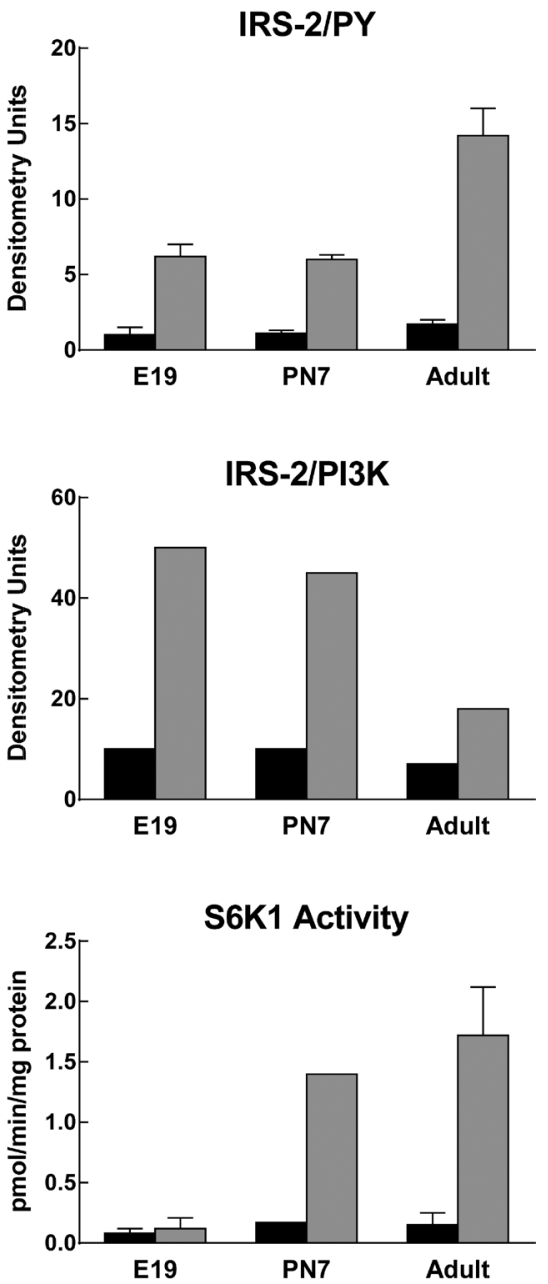

Figure 2

Developmental changes in the expression and activity of key components of the insulin signaling pathway. The data shown in this figure were derived from previously published studies (Anand et al. 2002, Khamzina et al. 2003). The graphs depict data from late gestation fetal rats (E19), newborn rat pups on postnatal day 7 (PN7), and adult male rats of approximately 5-6 weeks of age. Animals at all three developmental time points were administered vehicle as a control (black bars) or insulin (grey bars) by intraperitoneal injection 15 min before being killed. The E19 fetuses were manipulated in situ during a Cesarean section. Results are shown as the mean of duplicate determinations or, where error bars are included, the mean \pm S.D. for triplicate determinations. The tyrosine phosphorylation of IRS1 and IRS2 (IRS1/PY and IRS2/PY, respectively) was determined by immunoprecipitation followed by western blotting. PI3K activity associated with IRS1 or IRS2 was determined by the application of a PI3K assay to immunoprecipitates. Akt and S6K1 activities were determined by immunoprecipitation kinase assays. Western blottings that demonstrated similar levels of Akt and S6K1 at all three developmental time points are not shown here. late in gestation in the fetal rat are largely independent of the growth-promoting effects of insulin. However, studies on enzymic differentiation suggest that cAMP-mediated counterregulatory hormones are biologically active during fetal life and are critical for enzymic differentiation.

This conclusion is further supported by studies on hepatic glycogen metabolism carried out more than 40 years ago. During the last third of gestation in the rat, there is a marked increase in hepatic glycogen content. This occurs in concert with induction of the key enzymes of glycogen metabolism, glycogen synthase, phosphorylase, and phosphorylase kinase (Gruppuso \& Brautigan 1989). While constituting an anabolic process that is insulin-mediated in the adult (Miller \& Larner 1973, Miller et al. 1973), the induction of glycogen synthase and accumulation of glycogen precede the late gestation rise in fetal plasma insulin concentrations (Mayor \& Cuezva 1985).

There is an established role for glucocorticoids in the induction of hepatic glycogenesis (Moses et al. 1981). Accumulation of hepatic glycogen in the late gestation fetal rat is markedly reduced if both maternal and fetal glucocorticoid synthesis is limited by the combination of maternal adrenalectomy and fetal hypophysectomy. Liver glycogen content is restored by the direct administration of glucocorticoid to the fetus (Jost 1961). This effect is likely mediated by the induction of glycogen synthase (Moses et al. 1981). In unperturbed fetal rats, administration of glucocorticoid can induce premature glycogen deposition (Greengard \& Dewey 1967).

With regard to the relevance of studies in the rat to human physiology, liver glycogen accumulation in the rat begins on day 18 of gestation (Devos \& Hers 1974), whereas in the human, liver glycogen accumulation is initiated during the first trimester on or about week 8 (Schwartz et al. 1975). It then continues throughout gestation. In both species, glycogen accumulation accompanies the appearance of glycogen synthase (Devos \& Hers 1974, Schwartz et al. 1975). These and other data indicate a limited role for insulin in liver differentiation during 
mid-gestation in the human, similar to the situation in the rat. In contrast, glucocorticoids appear to be essential.

\section{Late gestation liver growth in the rat: clues to the physiologic regulation of liver development}

During the last 5 days of gestation in the rat, there is a tripling of liver mass, total liver DNA, and total liver protein. Owing to a corresponding decline in the liver's hematopoietic element, there is an increase in relative hepatocyte mass. A number of years ago, we began to focus on the signaling mechanisms that accounted for this extraordinary rate of somatic growth, and the relationship between fetal growth control and the growth of a similar magnitude that occurs in liver regeneration following partial hepatectomy.

To better understand the signaling mechanisms regulating late gestation hepatocyte development in the rat, we employed primary cultures using defined conditions (Curran et al. 1993). In a comparison of insulin with two factors that are mitogenic for hepatocytes, transforming growth factor $\alpha$ (TGF $\alpha)$ and hepatocyte growth factor (HGF), we found that late gestation fetal hepatocytes did not exhibit synergy between insulin and these two growth factors (Gruppuso et al. 1994). In addition, TGF $\alpha$ and HGF, but not insulin, induced activation of the Erk mitogenactivated protein kinase pathway in primary fetal hepatocyte cultures (Gruppuso et al. 1994). We interpreted these studies as indicating that insulin, while it might serve a hepatotrophic role in vivo, is not a mitogen for late gestation fetal rat hepatocytes.

In our subsequent studies, a caveat to this interpretation emerged. Having examined the response of cultured fetal hepatocytes to insulin and the growth factors mentioned above, we undertook studies on the regulation of mitogenic signaling pathways in vivo. Our approach to these studies was to administer growth factors directly to the fetuses by intraperitoneal injection in situ. As noted above, this approach demonstrated a marked impairment of insulin signaling to PI3K in the late gestation fetus (Anand et al. 2002). More unexpected was the observation that mitogen-induced activation of MAPK1/3 signaling was markedly attenuated in the fetus (Boylan \& Gruppuso 1994, 1996). Like other so-called MAP kinase pathways, the MAPK1/3 pathway consists of a cascade of three kinases. We found that the uncoupling of this pathway in late gestation fetal liver was accounted for by an interruption of signaling from the intermediate kinase in the pathway, MEK, to the terminal MAPKs
(Boylan \& Gruppuso 1998). This unusual circumstance may be attributable to differences in the expression or function of scaffolding proteins that provide for functional organization of the pathway (Sacks 2006), or to dual specificity phosphatases that can act as negative regulators of this pathway (Keyse 2008). While we have not identified these or other specific mechanisms as accounting for the uncoupling of MEK signaling to MAPK1/3, this observation supported the hypothesis that late gestation liver growth, unlike liver regeneration in the adult (Fausto et al. 1995), is not dependent on the actions of trophic factors acting through this well-characterized signaling pathway.

Further support for this conclusion came from studies on another critical pathway for cellular growth, which involves the mechanistic target of rapamycin (mTOR) (Laplante \& Sabatini 2012, Albert \& Hall 2015). mTOR participates in two signaling complexes, mTORC1 and mTORC2. mTORC1, the canonical target of the immunosuppressive drug rapamycin, is a key regulator of protein synthesis, cell growth, and gene expression. mTORC1 is regulated directly by nutrient availability and by growth factor receptor tyrosine kinases. Given the high rate of asynchronous hepatocyte proliferation in the late gestation rodent fetus, we hypothesized that mTORC1 signaling would be constitutively active and that inhibition of mTORC1 by rapamycin would potently inhibit fetal hepatocyte proliferation in vivo.

In a series of studies aimed at testing this hypothesis, we administered rapamycin to late gestation fetal rats by i.p. injection in situ. DNA synthesis was assessed as the incorporation of bromodeoxyuridine into DNA, which we detected using immunohistochemistry. These experiments (Boylan et al. 2001) yielded an unexpected result; fetal hepatocyte proliferation in the late gestation (E19) fetus was independent of mTORC1 signaling. In further experiments, we showed that the translation of mRNAs with complex $5^{\prime}$ oligopyrimidine tracts, so-called 5'TOP mRNAs, was also insensitive to rapamycin-induced inhibition of mTORC1 signaling (Gruppuso et al. 2008, Boylan et al. 2015). These results were in sharp contrast to those obtained in adult rats subjected to refeeding after fasting or to partial hepatectomy. In fact, liver regeneration is exquisitely sensitive to rapamycin-induced inhibition of mTORC1 (Boylan et al. 2001), consistent with the established role of a number of mitogenic signaling pathways in liver regeneration (Fausto et al. 1995).

Although manipulation of mTORC1 activity does not have deleterious effects in utero, mice expressing a constitutively active form of RagA, a GTPase involved in the activation of mTORC1 by amino acids, die shortly

Published by Bioscientifica Ltd. 
after birth due to the inability to induce autophagy and maintain glucose homeostasis (Efeyan et al. 2013). In contrast to the wealth of data on mTORC1, the pathways upstream and downstream of mTORC2 are less well understood. mTORC2 is responsive to insulin and is involved in the regulation of the actin cytoskeleton, cellular metabolism, and aging (Zoncu et al. 2011, Lamming et al. 2012). In adult liver, mTORC2 induces glycolysis through activation of Akt and is essential for the expression of genes involved in lipogenesis (Hagiwara et al. 2012, Yuan et al. 2012). We performed genomic and phosphoproteomic analyses in mice in which Rictor, an essential component of mTORC2, was deleted. We did so to better characterize the physiologic role of mTORC2. We showed that mTORC2 regulated the expression of a large set of genes involved in intermediary metabolism and in ribosome and proteasome biogenesis (Lamming et al. 2013). It is likely that both mTORC1 and mTORC2 signaling play a critical role in fetal metabolism and adaptation of the newborn during the early postnatal period.

From these studies, a picture emerges in which fetal liver growth in the late gestation rat is 'mitogen-independent'. That is, the increase in hepatocyte mass that occurs at the end of gestation in the rat is largely independent of the mitogenic signaling pathways that are active in the adult rat (illustrated in Fig. 3).

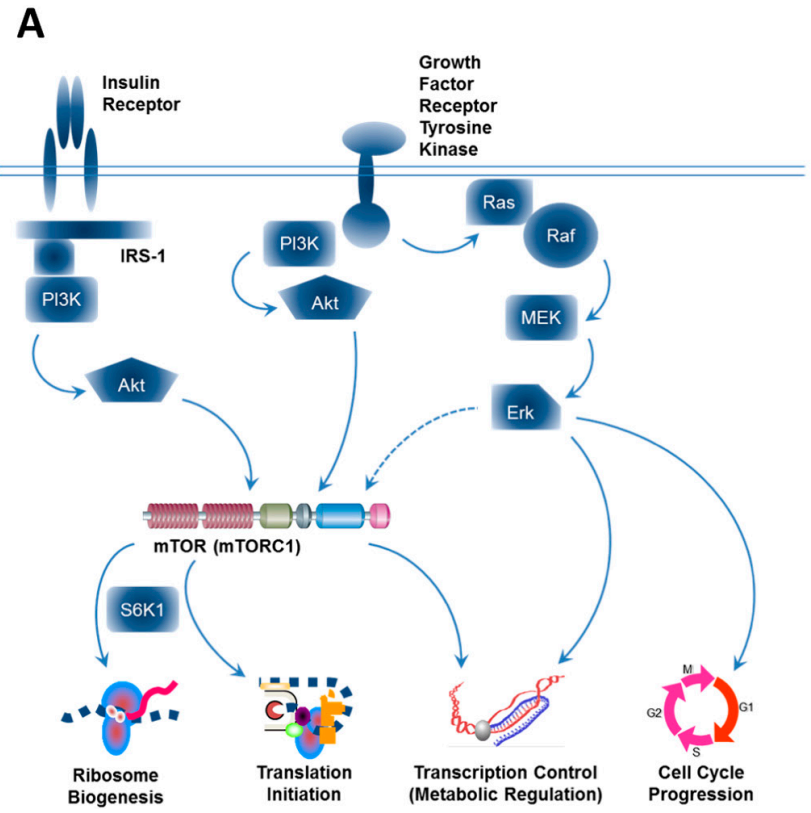

\section{The role of insulin in liver growth and physiology in the nonhuman primate}

With regard to the role of insulin in late gestation liver development in humans, studies carried out in nonhuman primates by Susa, Schwartz and co-workers in the 1970s and 1980s (McCormick et al. 1979, Susa et al. 1979, Susa et al. 1984a,b) and Susa and Schwartz (1985) are particularly informative. These investigators were focused on the role of fetal insulin in the diabetic fetopathy in pregnancy. They implanted osmotic minipumps into fetal rhesus monkeys to achieve a constant infusion of insulin for the last 3 weeks of gestation. Like the human infant of a diabetic mother, hyperinsulinemia resulted in newborn rhesus monkeys with soft tissue hyperplasia, elevated erythropoietin levels, commensurate polycythemia, and impaired lung maturation in utero (Susa et al. 1979, 1984b). Supraphysiologic insulin levels, consistent with those seen in the human fetus of a diabetic mother, resulted in an increase in hepatic mass.

Fetal hyperinsulinemia was associated with reduced activity of two hepatic gluconeogenic enzymes: glucose6-phosphatase and phosphoenolpyruvate carboxykinase (McCormick et al. 1979). The activities of key lipogenic enzymes, such as fatty acid synthase complex, glucose6-phosphate dehydrogenase, and ATP citrate lyase were increased (McCormick et al. 1979, Susa et al. 1984a).

\section{B}

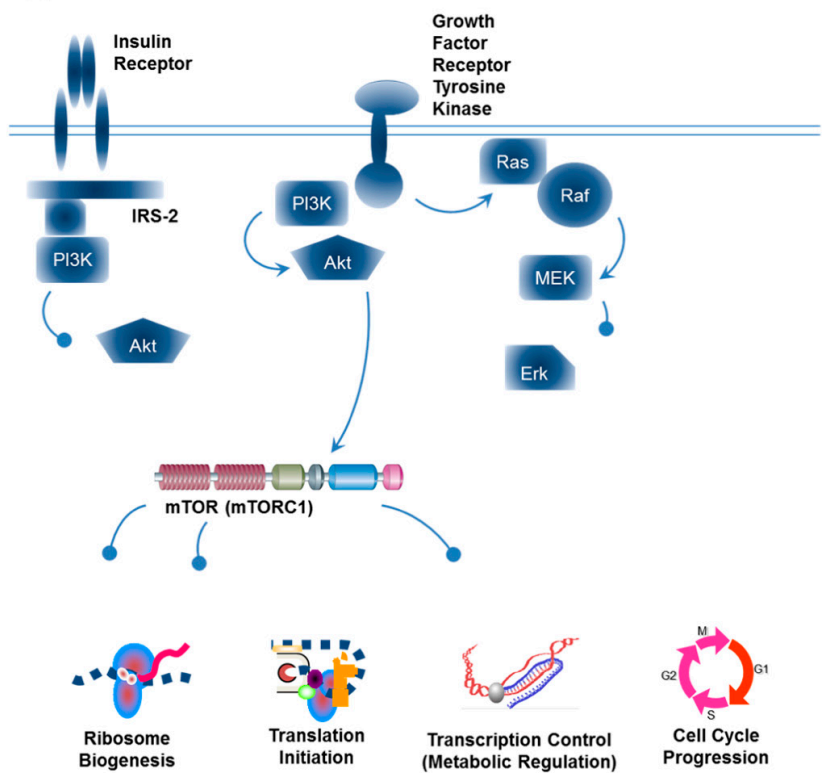

Figure 3

Hepatic insulin- and growth factor-mediated mitogenic signaling pathways in the rat. The diagrams represent a distillation of the data on mitogenic signaling in adult liver (panel A) vs late gestation fetal liver (panel B). 
In contrast, glycolytic enzymes and glycogen metabolism were unaffected.

These data indicate that insulin exerts effects on liver enzymic differentiation in the late gestation primate fetus. This may be interpreted as indicating that hepatic insulin signaling couples late in gestation in the primate, a developmental time point beyond that which corresponds to late gestation in the rat. The observations on primate are consistent with an evolving role for insulin in hepatic enzymic differentiation in the human as gestation proceeds.

\section{Maternal nutrition and fetal programing}

The developmental origins of health and disease hypothesis states that perturbations of the intrauterine environment can result in long-term effects on gene expression through changes to the epigenome, and that these epigenetic effects can lead to increased risk of developing diseases later in life (Waterland \& Michels 2007). Experimental and epidemiologic studies suggest that alterations in maternal nutrition during pregnancy and/or lactation lead to changes in fetal organ development and the programing of metabolic pathways (Barker 2012). A wealth of studies has shown a correlation between infant birth weight and risk of developing metabolic disease. Early studies by Barker et al. (1989) focused on the effects of maternal undernutrition and low birth weight. As in humans, caloric restriction during mid-gestation to late gestation in the rat results in decreased birth weight and predisposition to glucose intolerance and type II diabetes later in life (Yuan et al. 2011). The liver is a target for fetal programing. Alterations in nutrient supply caused by either uteroplacental insufficiency or protein restriction result in changes in hepatic structure and function, ultimately leading to altered expression of glucose-6phosphatase, phosphoenolpyruvate carboxykinase, and fructose bisphosphatase (Burns et al. 1997, Desai et al. $1997 a, b$, Lane et al. 2002). Alterations in histone posttranslational modifications within the promoter regions of PGC1, a key regulator of gluconeogenic enzymes, and carnitine palmitoyltransferase 1 , a rate-limiting transporter in fatty acid oxidation, persist postnatally in intrauterine growth-retarded animals and are thought to underlie many of the changes in gene expression (Lane et al. 2001, 2002, Fu et al. 2004).

There is growing interest in the potential for detrimental effects of maternal obesity and fetal overnutrition on the offspring. A number of epidemiologic studies have shown an association between maternal body mass index and gestational diabetes and increased offspring adiposity, type II diabetes, and nonalcoholic fatty liver disease (Lake et al. 1997, Dabelea et al. 2000, Boney et al. 2005, Stewart et al. 2013, Gademan et al. 2014). A number of animal models have provided insight into the molecular mechanisms underlying altered fetal programing in response to maternal obesity and overnutrition. These include alterations in food intake, increased oxidative stress, and dysregulated pancreatic and adipose function (Ozanne et al. 2011). As in undernutrition, altered epigenetic programing is believed to underlie many of the effects of maternal overnutrition, although the molecular mechanisms resulting in the common phenotype of increased risk of metabolic syndrome are most likely distinct.

\section{The fetal hepatocyte phenotype and cell-based therapy for liver disease}

Our studies characterizing fetal hepatocyte proliferation in the late gestation fetal rat as 'mitogen-independent' led us to consider the possibility that these cells would have the capacity to repopulate an injured adult liver. Such a capacity had been attributed earlier to midgestation fetal rat hepatoblasts (Dabeva et al. 2000, Oertel et al. 2008) and to late gestation fetal epithelial cells expressing cholangiocyte markers (Simper-Ronan et al. 2006). In addition to its implications for fetal metabolism and the perinatal transition, studies on mechanisms of fetal liver development are relevant to a cell-based therapeutic approach for liver disease. The only therapy currently available for liver failure associated with acute or chronic liver injury is transplantation. However, the lack of tissue available for transplant has hampered the success of this therapy (Kim et al. 2015). The concept of hepatocyte transplantation as an alternative to liver organ transplantation holds great potential. However, it also presents numerous challenges and thus far has shown limited efficacy due to the limited replicative potential of the adult cells used for transplantation (Hansel et al. 2014). The identification of the optimal source of cells for transplant and the elucidation of the effect of the liver microenvironment on these cells are key areas of future research.

As noted above, we hypothesized that the mitogen independence and relatively well-differentiated phenotype of late gestation fetal rat hepatocytes would allow these cells to proliferate and restore functional liver mass upon transplantation to an injured adult liver. We utilized the well-established dipeptidyl peptidase 4 (DPP4) transplant model developed by Thompson et al. (1991).

Published by Bioscientifica Ltd. 
This model takes advantage of a naturally occurring inactivating mutation in the $D p p 4$ gene present in German Fischer rats. This allows for the syngeneic transplantation of cells isolated from American Fischer rats (DPP4+) into German Fischer (DPP4-) hosts without the need to mark cells by transfection or other means. Pretreatment of the DPP4- hosts with mitomycin C followed by $2 / 3$ partial hepatectomy at the time of transplantation blocks endogenous adult hepatocyte proliferation, thus providing a selective growth advantage to the transplanted cells (Brilliant et al. 2009). We immunoisolated DPP4+

LAP-

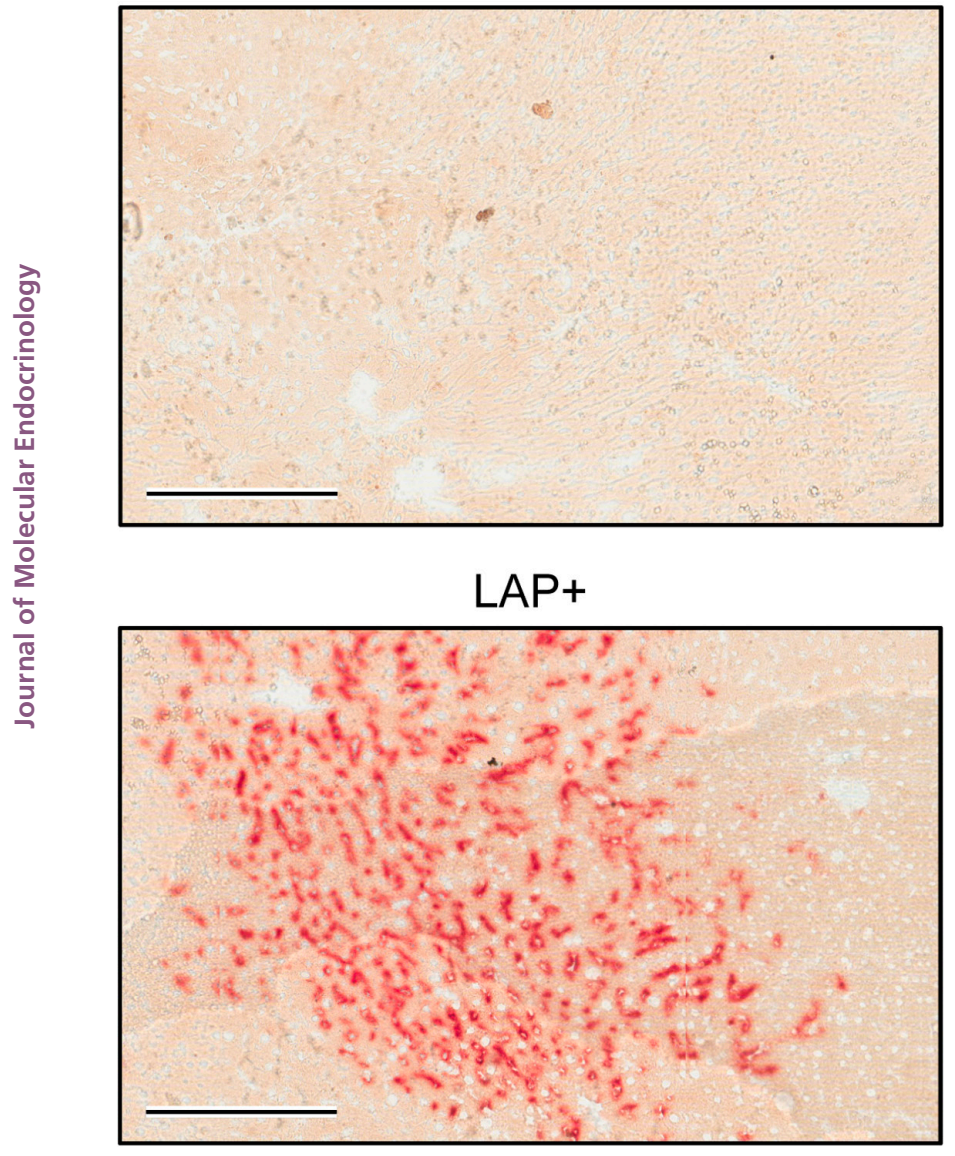

Figure 4

Liver repopulation by late gestation E19 fetal hepatocytes. DPPIV+ E19 fetal liver cells were immuno-isolated using a monoclonal antibody against the hepatic marker LAP that was conjugated to micromagnetic beads. The LAP+ and LAP- cell fractions were transplanted into a DPP4adult male host pretreated with mitomycin $C$ and $2 / 3$ partial hepatectomy. Histochemical staining for DPP4 was performed on cryosections from DPP4- hosts 1 month after transplantation with DPP4+ fetal cells that were either LAP+ or LAP-. DPP4+ colonies were observed following transplantation with LAP+ cells indicating that late gestation fetal hepatocytes were capable of liver repopulation, while the LAPfraction devoid of hepatocytes did not form colonies. Representative images are shown at 20x magnification. Scale bar $=200 \mu \mathrm{m}$. late gestation (ED19) fetal rat hepatocytes based on the expression of the hepatic marker leucine aminopeptidase (LAP) (Mowery \& Hixson 1991). The LAP+ and LAPfractions isolated from DPP4+ American Fischer fetal rats were transplanted via splenic injection into pretreated DPP4- German Fischer adult hosts. One month following transplantation, the LAP+ fetal cells had formed numerous hepatic and endothelial colonies, while the LAP- cells did not repopulate the injured adult liver (Fig. 4). These studies indicate that a fuller understanding of the fetal hepatocyte phenotype might contribute to the selection of optimal cell sources for transplantation. Future studies in this area may also provide strategies for expansion of cell sources in vitro and other tissue engineering strategies necessary for successful cell-based therapy for liver disease.

\section{Conclusions and future perspectives}

The process of liver development and attainment of differentiated function during the fetal and early postnatal period is an intricate temporal process that relies on a shifting and complex network of signaling pathways. An extensive literature that includes our own studies indicates that the systems governing liver growth and functional differentiation during mid-to-late fetal development differ from those that account for the regeneration of adult liver under conditions of liver injury or reduced mass.

Recent research has shown that epigenetic mechanisms including DNA methylation and histone modifications are involved in patterning the liver and regulating the ontogeny of metabolic enzymes and transporters (Xu \& Zaret 2012, Moscovitz \& Aleksunes 2013). Additional research is needed to understand how epigenetic, transcriptional, translational, and posttranslational mechanisms intersect to control normal liver development. Future studies will likely involve a combination of global omics-based approaches coupled with human tissue and physiologic animal models. Such an approach offers a more complete understanding of liver development and functional differentiation, which would relate directly to the physiology and pathophysiology of metabolic adaptation in the newborn. As has been seen more recently, ongoing research on liver development may also contribute to the elucidation of mechanisms involved in the developmental origins of adult metabolic dysregulation. All of this work has the potential to contribute to the prevention and treatment of metabolic disorders, liver failure, and liver carcinogenesis.

Published by Bioscientifica Ltd 


\section{Declaration of interest}

The authors declare that there is no conflict of interest that could be perceived as prejudicing the impartiality of the research reported.

\section{Funding}

The work reported herein was supported by the National Institutes of Health (grants R01HD024455 and R01DK100301).

\section{Acknowledgments}

The authors thank Joan Boylan for her helpful discussions and comments regarding the contents of this paper.

\section{References}

Albert V \& Hall MN 2015 mTOR signaling in cellular and organismal energetics. Current Opinion in Cell Biology 33 55-66. (doi:10.1016/ j.ceb.2014.12.001)

Anand P, Boylan JM, Ou Y \& Gruppuso PA 2002 Insulin signaling during perinatal liver development in the rat. American Journal of Physiology: Endocrinology and Metabolism 283 E844-E852. (doi:10.1152/ajpendo.00111.2002)

Barker DJ 2012 Sir Richard Doll Lecture. Developmental origins of chronic disease. Public Health 126 185-189. (doi:10.1016/ j.puhe.2011.11.014)

Barker DJ, Osmond C, Golding J, Kuh D \& Wadsworth ME 1989 Growth in utero, blood pressure in childhood and adult life, and mortality from cardiovascular disease. BMJ 298 564-567. (doi:10.1136/ bmj.298.6673.564)

Boney CM, Verma A, Tucker R \& Vohr BR 2005 Metabolic syndrome in childhood: association with birth weight, maternal obesity, and gestational diabetes mellitus. Pediatrics 115 e290-296. (doi:10.1542/ peds.2004-1808)

Bort R, Signore M, Tremblay K, Martinez Barbera JP \& Zaret KS 2006 Hex homeobox gene controls the transition of the endoderm to a pseudostratified, cell emergent epithelium for liver bud development. Developmental Biology 290 44-56. (doi:10.1016/j. ydbio.2005.11.006)

Boylan JM, Anand P \& Gruppuso PA 2001 Ribosomal protein S6 phosphorylation and function during late gestation liver development in the rat. Journal of Biological Chemistry $\mathbf{2 7 6}$ 44457-44463. (doi:10.1074/jbc.m103457200)

Boylan JM \& Gruppuso PA 1994 In vitro and in vivo regulation of hepatic mitogen-activated protein kinases in fetal rats. American Journal of Physiology: Gastrointestinal and Liver Physiology 267 G1078-G1086.

Boylan JM \& Gruppuso PA 1996 A comparative study of the hepatic mitogen-activated protein kinase and Jun-NH 2 -terminal kinase pathways in the late-gestation fetal rat. Cell Growth \& Differentiation 7 1261-1269.

Boylan JM \& Gruppuso PA 1998 Uncoupling of hepatic, epidermal growth factor-mediated mitogen-activated protein kinase activation in the fetal rat. Journal of Biological Chemistry 273 3784-3790. (doi:10.1074/jbc.273.6.3784)

Boylan JM, Sanders JA, Neretti N \& Gruppuso PA 2015 Profiling of the fetal and adult rat liver transcriptome and translatome reveals discordant regulation by the mechanistic target of rapamycin (mTOR). American Journal of Physiology: Regulatory, Integrative and Comparative Physiology 309 R22-R35. (doi:10.1152/ ajpregu.00114.2015)

Brilliant KE, Mills DR, Callanan HM \& Hixson DC 2009 Engraftment of syngeneic and allogeneic endothelial cells, hepatocytes and cholangiocytes into partially hepatectomized rats previously treated with mitomycin C. Transplantation 88 486-495. (doi:10.1097/ TP.0b013e3181b0b98a)

Burns SP, Desai M, Cohen RD, Hales CN, Iles RA, Germain JP, Going TC \& Bailey RA 1997 Gluconeogenesis, glucose handling, and structural changes in livers of the adult offspring of rats partially deprived of protein during pregnancy and lactation. Journal of Clinical Investigation 100 1768-1774. (doi:10.1172/JCI119703)

Cascio S \& Zaret KS 1991 Hepatocyte differentiation initiates during endodermal-mesenchymal interactions prior to liver formation. Development 113 217-225. (doi:10.1016/j.jpurol.2015.07.006)

Collardeau-Frachon S \& Scoazec JY 2008 Vascular development and differentiation during human liver organogenesis. Anatomical Record 291 614-627. (doi:10.1002/ar.20679)

Cowett RM 2011 Role of glucoregulatory ormones in hepatic glucose metabolism during the perinatal period. In Fetal and Neonatal Physiology, 4th edn, pp 550-559. Eds RA Polin, WW Fox \& SH Abman. Philadelphia, PA, USA: Elsevier Saunders.

Cumano A \& Godin I 2007 Ontogeny of the hematopoietic system. Annual Review of Immunology 25 745-785. (doi:10.1146/annurev. immunol.25.022106.141538)

Curran TR Jr, Bahner RI Jr, Oh W \& Gruppuso PA 1993 Mitogenindependent DNA synthesis by fetal rat hepatocytes in primary culture. Experimental Cell Research 209 53-57. (doi:10.1006/ excr.1993.1284)

Dabelea D, Hanson RL, Lindsay RS, Pettitt DJ, Imperatore G, Gabir MM, Roumain J, Bennett PH \& Knowler WC 2000 Intrauterine exposure to diabetes conveys risks for type 2 diabetes and obesity: A study of discordant sibships. Diabetes 49 2208-2211. (doi:10.2337/ diabetes.49.12.2208)

Dabeva MD, Petkov PM, Sandhu J, Oren R, Laconi E, Hurston E \& Shafritz DA 2000 Proliferation and differentiation of fetal liver epithelial progenitor cells after transplantation into adult rat liver. American Journal of Pathology 156 2017-2031. (doi:10.1016/S00029440(10)65074-2)

Desai M, Byrne CD, Meeran K, Martenz ND, Bloom SR \& Hales CN $1997 a$ Regulation of hepatic enzymes and insulin levels in offspring of rat dams fed a reduced-protein diet. American Journal of Physiology: Gastrointestinal and Liver Physiology 273 G899-G904.

Desai M, Byrne CD, Zhang J, Petry CJ, Lucas A \& Hales CN 1997b Programming of hepatic insulin-sensitive enzymes in offspring of rat dams fed a protein-restricted diet. American Journal of Physiology: Gastrointestinal and Liver Physiology 272 G1083-G1090.

Devos P \& Hers HG 1974 Glycogen metabolism in the liver of the foetal rat. Biochemical Journal 140 331-340. (doi:10.1042/ bj1400331)

Efeyan A, Zoncu R, Chang S, Gumper I, Snitkin H, Wolfson RL, Kirak O, Sabatini DD \& Sabatini DM 2013 Regulation of mTORC1 by the Rag GTPases is necessary for neonatal autophagy and survival. Nature 493 679-683. (doi:10.1038/nature11745)

Fausto N, Laird AD \& Webber EM 1995 Liver regeneration. 2. Role of growth factors and cytokines in hepatic regeneration. FASEB Journal 9 1527-1536.

Fu Q, McKnight RA, Yu X, Wang L, Callaway CW \& Lane RH 2004 Uteroplacental insufficiency induces site-specific changes in histone H3 covalent modifications and affects DNA-histone H3 positioning in day 0 IUGR rat liver. Physiological Genomics 20 108-116. (doi:10.1152/physiolgenomics.00175.2004)

Gademan MG, Vermeulen M, Oostvogels AJ, Roseboom TJ, Visscher TL, van Eijsden M, Twickler MT \& Vrijkotte TG 2014 Maternal prepregancy BMI and lipid profile during early pregnancy are independently associated with offspring's body composition at age 5-6 years: the ABCD study. PLoS ONE 9 e94594. (doi:10.1371/ journal.pone.0094594)

Girard JR, Cuendet GS, Marliss EB, Kervran A, Rieutort M \& Assan R 1973 Fuels, hormones, and liver metabolism at term and during the

Published by Bioscientifica Ltd. 
early postnatal period in the rat. Journal of Clinical Investigation $\mathbf{5 2}$ 3190-3200. (doi:10.1172/JCI107519)

Gordillo M, Evans T \& Gouon-Evans V 2015 Orchestrating liver development. Development 142 2094-2108. (doi:10.1242/ dev.114215)

Greengard O 1969 Enzymic differentiation in the mammalian liver. Science 163 891-895. (doi:10.1126/science.163.3870.891)

Greengard O \& Dewey HK 1967 Initiation by glucagon of the premature development of tyrosine aminotransferase, serine dehydratase, and glucose-6-phosphatase in fetal rat liver. Journal of Biological Chemistry 242 2986-2991.

Gruppuso PA, Boylan JM, Bienieki TC \& Curran TR Jr 1994 Evidence for a direct hepatotrophic role for insulin in the fetal rat: implications for the impaired hepatic growth seen in fetal growth retardation. Endocrinology 134 769-775. (doi:10.1210/endo.134.2.8299572)

Gruppuso PA \& Brautigan DL 1989 Induction of hepatic glycogenesis in the fetal rat. American Journal of Physiology: Endocrinology and Metabolism 256 E49-E54.

Gruppuso PA, Curran TR, Mead JE, Fausto N \& Oh W 1991 Fetal growth factors as determinants of intrauterine hepatic growth. Diabetes 2 (40 Supplement) 51-55. (doi:10.2337/diab.40.2.S51)

Gruppuso PA, Tsai SW, Boylan JM \& Sanders JA 2008 Hepatic translation control in the late-gestation fetal rat. American Journal of Physiology: Regulatory, Integrative and Comparative Physiology 295 R558-R567 (doi:10.1152/ajpregu.00091.2008)

Hagiwara A, Cornu M, Cybulski N, Polak P, Betz C, Trapani F, Terracciano L, Heim MH, Ruegg MA \& Hall MN 2012 Hepatic mTORC2 activates glycolysis and lipogenesis through Akt, glucokinase, and SREBP1c. Cell Metabolism 15 725-738. (doi:10.1016/j.cmet.2012.03.015)

Hansel MC, Gramignoli R, Skvorak KJ, Dorko K, Marongiu F, Blake W, Davila J \& Strom SC 2014 The history and use of human hepatocytes for the treatment of liver diseases: the first 100 patients. Current Protocols in Toxicology 62 11-14. (doi:10.1002/0471140856. tx1412s62)

Haruna Y, Saito K, Spaulding S, Nalesnik MA \& Gerber MA 1996 Identification of bipotential progenitor cells in human liver development. Hepatology 23 476-481. (doi:10.1002/ hep.510230312)

Hutchins GM \& Moore GW 1988 Growth and asymmetry of the human liver during the embryonic period. Pediatric Pathology 8 17-24. (doi:10.3109/15513818809022276)

Jost A 1961 The role of fetal hormones in prenatal development. Harvey Lectures 55 201-226.

Keyse SM 2008 Dual-specificity MAP kinase phosphatases (MKPs) and cancer. Cancer and Metastasis Reviews 27 253-261. (doi:10.1007/ s10555-008-9123-1)

Khamzina L, Gruppuso PA \& Wands JR 2003 Insulin signaling through insulin receptor substrate 1 and 2 in normal liver development. Gastroenterology 125 572-585. (doi:10.1016/S0016-5085(03)00893-X)

Kim WR, Lake JR, Smith JM, Skeans MA, Schladt DP, Edwards EB, Harper AM, Wainright JL, Snyder JJ, Israni AK, et al. 2015 OPTN/SRTR 2013 Annual Data Report: Liver. American Journal of Transplantation 2 (15 Supplement) 1-28.

Kyrmizi I, Hatzis P, Katrakili N, Tronche F, Gonzalez FJ \& Talianidis I 2006 Plasticity and expanding complexity of the hepatic transcription factor network during liver development. Genes \& Development 20 2293-2305. (doi:10.1101/gad.390906)

Lake JK, Power C \& Cole TJ 1997 Child to adult body mass index in the 1958 British birth cohort: associations with parental obesity. Archives of Disease in Childhood 77 376-381. (doi:10.1136/ adc.77.5.376)

Lamming DW, Demirkan G, Boylan JM, Mihaylova MM, Peng T, Ferreira J, Neretti N, Salomon A, Sabatini DM \& Gruppuso PA 2013 Hepatic signaling by the mechanistic target of rapamycin complex 2 (mTORC2). FASEB Journal 28 300-315. (doi:10.1096/fj.13-237743)
Lamming DW, Ye L, Katajisto P, Goncalves MD, Saitoh M, Stevens DM, Davis JG, Salmon AB, Richardson A, Ahima RS, et al. 2012 Rapamycin-induced insulin resistance is mediated by mTORC2 loss and uncoupled from longevity. Science 335 1638-1643. (doi:10.1126/ science.1215135)

Lane RH, Kelley DE, Gruetzmacher EM \& Devaskar SU 2001 Uteroplacental insufficiency alters hepatic fatty acid-metabolizing enzymes in juvenile and adult rats. American Journal of Physiology: Regulatory, Integrative and Comparative Physiology 280 R183-R190.

Lane RH, MacLennan NK, Hsu JL, Janke SM \& Pham TD 2002 Increased hepatic peroxisome proliferator-activated receptorgamma coactivator-1 gene expression in a rat model of intrauterine growth retardation and subsequent insulin resistance. Endocrinology 143 2486-2490. (doi:10.1210/ endo.143.7.8898)

Laplante M \& Sabatini DM 2012 mTOR signaling in growth control and disease. Cell 149 274-293. (doi:10.1016/j.cell.2012.03.017)

Mayor F \& Cuezva JM 1985 Hormonal and metabolic changes in the perinatal period. Biology of the Neonate $\mathbf{4 8}$ 185-196. (doi:10.1159/000242171)

McCormick KL, Susa JB, Widness JA, Singer DB, Adamsons K \& Schwartz R 1979 Chronic hyperinsulinemia in the fetal rhesus monkey: effects on hepatic enzymes active in lipogenesis and carbohydrate metabolism. Diabetes 28 1064-1068. (doi:10.2337/ diab.28.12.1064)

Miller TB Jr, Hazen R \& Larner J 1973 An absolute requirement for insulin in the control of hepatic glycogenesis by glucose. Biochemical and Biophysical Research Communications 53 466-474 (doi:10.1016/0006-291X(73)90685-2)

Miller TB Jr \& Larner J 1973 Mechanism of control of hepatic glycogenesis by insulin. Journal of Biological Chemistry $\mathbf{2 4 8}$ 3483-3488.

Moscovitz JE \& Aleksunes LM 2013 Establishment of metabolism and transport pathways in the rodent and human fetal liver. International Journal of Molecular Sciences 14 23801-23827. (doi:10.3390/ ijms141223801)

Moses SW, Pines M \& Bashan N 1981 Hormonal control of fetal liver glycogen metabolism. In Metabolic Adaptation to Extrauterine Life: The Antenatal Role of Carbohydrates and Energy Metabolism, pp 9-26. Ed R De Meyer. Boston, MA: Martinus Nijhoff Publishers.

Mowery J \& Hixson DC 1991 Detection of cell-CAM 105 in the pericanalicular domain of the rat hepatocyte plasma membrane. Hepatology 13 47-56. (doi:10.1002/hep.1840130108)

Nava S, Westgren M, Jaksch M, Tibell A, Broome U, Ericzon BG \& Sumitran-Holgersson S 2005 Characterization of cells in the developing human liver. Differentiation 73 249.-260 (doi:10.1111/j.1432-0436.2005.00019.x)

Oertel M, Menthena A, Chen YQ, Teisner B, Jensen CH \& Shafritz DA 2008 Purification of fetal liver stem/progenitor cells containing all the repopulation potential for normal adult rat liver. Gastroenterology 134 823-832. (doi:10.1053/ j.gastro.2008.01.007)

Ozanne SE, Sandovici I \& Constancia M 2011 Maternal diet, aging and diabetes meet at a chromatin loop. Aging 3 548-554. (doi:10.18632/ aging.100330)

Porterfield SP 1979 The effects of growth hormone, thyroxine and insulin on the activities of reduced nicotinamide adenine dinucleotide phosphate dehydrogenase, glucose-6-phosphatase and glycogen phosphorylase in fetal rat liver. Hormone and Metabolic Research 11 444-448. (doi:10.1055/s-0028-1092757)

Sacks DB 2006 The role of scaffold proteins in MEK/ERK signalling. Biochemical Society Transactions 34 833-836. (doi:10.1042/ BST0340833)

Schwartz AL, Raiha NC \& Rall TW 1975 Hormonal regulation of glycogen metabolism in human fetal liver. I. Normal development and effects of dibutyryl cyclic AMP, glucagon, 
and insulin in liver explants. Diabetes 24 1101-1112. (doi:10.2337/diab.24.12.1101)

Severn CB 1971 A morphological study of the development of the human liver. I. Development of the hepatic diverticulum. American Journal of Anatomy 131 133-158. (doi:10.1002/aja.1001310202)

Shiojiri N, Lemire JM \& Fausto N 1991 Cell lineages and oval cell progenitors in rat liver development. Cancer Research 51 2611-2620.

Si-Tayeb K, Lemaigre FP \& Duncan SA 2010 Organogenesis and development of the liver. Developmental Cell 18 175-189. (doi:10.1016/j.devcel.2010.01.011)

Simper-Ronan R, Brilliant K, Flanagan D, Carreiro M, Callanan H, Sabo E \& Hixson DC 2006 Cholangiocyte marker-positive and -negative fetal liver cells differ significantly in their ability to regenerate the livers of adult rats exposed to retrorsine. Development 133 4269-4279. (doi:10.1242/dev.02589)

Stewart MS, Heerwagen MJ \& Friedman JE 2013 Developmental programming of pediatric nonalcoholic fatty liver disease: redefining the "first hit". Clinical Obstetrics \& Gynaecology 56 577-590. (doi:10.1097/GRF.0b013e3182a09760)

Susa JB, McCormick KL, Widness JA, Singer DB, Oh W, Adamsons K \& Schwartz R 1979 Chronic hyperinsulinemia in the fetal rhesus monkey: effects on fetal growth and composition. Diabetes $\mathbf{2 8}$ 1058-1063. (doi:10.2337/diab.28.12.1058)

Susa JB, Gruppuso PA, Widness JA, Domenech M, Clemons GK, Sehgal P \& Schwartz R 1984a Chronic hyperinsulinemia in the fetal rhesus monkey: effects of physiologic hyperinsulinemia on fetal substrates, hormones, and hepatic enzymes. American Journal of Obstetrics \& Gynecology 150 415-420. (doi:10.1016/S0002-9378(84)80150-7)

Susa JB, Neave C, Sehgal P, Singer DB, Zeller WP \& Schwartz R $1984 b$ Chronic hyperinsulinemia in the fetal Rhesus monkey: effects of physiologic hyperinsulinemia on fetal growth and composition. Diabetes 33 656-660. (doi:10.2337/diab.33.7.656)

Susa JB \& Schwartz R 1985 Effects of hyperinsulinemia in the primate fetus. Diabetes 2 (Supplement 34) 36-41. (doi:10.2337/diab.34.2.S36)

Thompson NL, Hixson DC, Callanan H, Panzica M, Flanagan D, Faris RA, Hong W, Hartel-Schenk S \& Doyle D 1991 A Fischer rat substrain deficient in dipeptidyl peptidase IV activity makes normal steady-state RNA levels and an altered protein. Biochemical Journal 273 497-502. (doi:10.1042/bj2730497)

Waterland RA \& Michels KB 2007 Epigenetic epidemiology of the developmental origins hypothesis. Annual Review of Nutrition $\mathbf{2 7}$ 363-388. (doi:10.1146/annurev.nutr.27.061406.093705)

Wilson JW, Groat CS \& Leduc EH 1963 Histogenesis of the liver. Annals of the New York Academy of Sciences 111 8-24 (doi:10.1111/j.1749-6632.1963.tb36945.x)

Xu CR \& Zaret KS 2012 Chromatin "pre-pattern" and epigenetic modulation in the cell fate choice of liver over pancreas in the endoderm. Nucleus 3 150-154. (doi:10.4161/ nucl.19321)

Yuan M, Pino E, Wu L, Kacergis M \& Soukas AA 2012 Identification of Akt-independent regulation of hepatic lipogenesis by mammalian target of rapamycin (mTOR) complex 2. Journal of Biological Chemistry 287 29579-29588. (doi:10.1074/jbc.M112.386854)

Yuan Q, Chen L, Liu C, Xu K \& Mao X 2011 Postnatal pancreatic islet beta cell function and insulin sensitivity at different stages of lifetime in rats born with intrauterine growth retardation. PLOS ONE 6 e25167. (doi:10.1371/journal.pone.0025167)

Zoncu R, Efeyan A \& Sabatini DM 2011 mTOR: From growth signa integration to cancer, diabetes and ageing. Nature Reviews Molecular and Cellular Biology 12 21-35. (doi:10.1038/nrm3025)

Received in final form 11 February 2016

Accepted 16 February 2016

Accepted Preprint published online 17 February 2016 http://jme.endocrinology-journals.org DOI: 10.1530/JME-15-0313
() 2016 Society for Endocrinology Printed in Great Britain
Published by Bioscientifica Ltd. 